\title{
Retrospective case series analysis of vestibuloplasty with free gingival graft and titanium mesh around dental implant
}

\author{
Jeong-Kui Ku*, Dae Ho Leem \\ Department of Oral and Maxillofacial Surgery, School of Dentistry and Institute of Oral Bioscience, Research Institute of Clinical \\ Medicine of Jeonbuk National University-Biomedical Research Institute of Jeonbuk National University Hospital, \\ Jeonbuk National University, Jeonju, Korea
}

\begin{abstract}
J Korean Assoc Oral Maxillofac Surg 2020;46:417-421)
Objectives: The purpose of this paper is to introduce an effective technique to easily obtain adequate amounts of keratinized gingiva and vestibular depth.

Materials and Methods: Free gingiva (vertical height $10 \mathrm{~mm}$ ) was harvested on the palatal mucosa and a partial thickness flap was elevated on the recipient site with same width as the free gingiva graft. After a conventional suture, a titanium mesh covered the graft and was fixed with miniscrews. Titanium mesh was removed $4.1 \pm 2.5$ weeks after surgery. The amount of keratinized gingiva and vestibular depth was measured at the final follow-up. Results: Nine patients (males 4, females 5; 53.9 \pm 14.1 years) who underwent bone graft surgery before vestibuloplasty were included. No free gingival graft failure or complications were encountered in any of the patients. The relapse rate for vestibular depth (23.3\%) was lower than that for keratinized gingiva (48.3\%) after $34.4 \pm 14.4$ months $(P=0.010)$.

Conclusion: Vestibuloplasty with a free gingival graft using titanium mesh could be achieved with an acceptable amount of keratinized gingiva and an appropriate vestibular depth around dental implant.
\end{abstract}

Key words: Dental implant, Tissue graft, Titanium, Vestibuloplasty

[paper submitted 2020. 2. 3 / revised 2020. 3. 3 / accepted 2020. 3. 13]

\section{Introduction}

In the widespread study of dental implant success, an appropriate amount of keratinized gingiva $(\mathrm{KG})$ around the implant has become a well-established success factor. A lack of KG could result in a shallow vestibular depth (VD) and positioning in the movable oral mucosa ${ }^{1}$. VD is defined as the distance from the uppermost boundary of the attached gingiva to the lowest boundary of the mucobuccal fold, and

\footnotetext{
Dae Ho Leem

Department of Oral and Maxillofacial Surgery, School of Dentistry, Jeonbuk National University, 567 Baekje-daero, Deokjin-gu, Jeonju 54896, Korea TEL: +82-63-250-2113 FAX: +82-63-250-2089

E-mail: idisho@jbnu.ac.kr

ORCID: https://orcid.org/0000-0001-6735-8275

*Current affiliation: Department of Oral and Maxillofacial Surgery, Section of Dentistry, Armed Forces Capital Hospital, Seongnam, Korea

(c) This is an open-access article distributed under the terms of the Creative Commons Attribution Non-Commercial License (http://creativecommons.org/ licenses/by-nc/4.0/), which permits unrestricted non-commercial use, distribution, and reproduction in any medium, provided the original work is properly cited. Copyright (C) 2020 The Korean Association of Oral and Maxillofacial Surgeons. All rights reserved.
}

as the functional space available for mastication and pronunciation. An appropriate VD is an important factor for maintaining good oral hygiene ${ }^{2}$. Resulting VD may be shallow when extensive surgical procedures are performed, such as a bone graft ${ }^{3}$. Although vestibuloplasty with free gingival graft (FGG) is a useful method for restoring deficient KG and VD, many studies have reported inadequate results because of scar formation and shrinkage after vestibuloplasty ${ }^{4}$. Therefore, to maintain a successful implant, it is essential to consider an effective method that not only increases KG but also provides appropriate VD.

Titanium is a useful biocompatible material in dentistry because it can resist bacterial infections and withstand high temperatures and corrosion ${ }^{5}$. In addition, when used with grafts, the sufficient rigidity of titanium mesh is expected to reduce dead space by exerting constant pressure over the graft. An approach to vestibuloplasty using titanium mesh and FGG was reported for the edentulous anterior mandible ${ }^{6}$. The titanium mesh used for this technique was flexible enough to provide even pressure across the graft to prevent dead space, minimize the need for stitches, and reduce operation time ${ }^{6}$. 
The aim of the current study was to analyze the KG and VD obtained around implants placed after vestibuloplasty using titanium mesh and FGG.

\section{Materials and Methods}

The study was approved by the Institutional Review Board of Jeonbuk National University Hospital (IRB No. 2017-11002-001), and the informed consent was waived by the IRB.

Data were collected through chart review of patients who showed a lack of both KG and VD ( $<1 \mathrm{~mm}$; Fig. 1) because of bone graft surgery with a muscle releasing incision for dental implantation and who underwent vestibuloplasty with a 10 -mm-wide free palatal gingiva covered with titanium mesh at Jeonbuk National University Hospital between May 2013 and March 2017.

Baseline of VD and $\mathrm{KG}$ was set to $10 \mathrm{~mm}$, which was the width of the graft. On follow-up, VD was measured from the highest margin of the gingiva to the lowest point of the vestibule, and the amount of KG was determined by measuring the vertical depth from the gingival crest to the movable alveolar mucosa. The amount of VD and KG was calculated as the average of the mesial, middle, and distal implant prosthetics.

Statistical analysis was performed using PASW Statistics for Windows (ver. 18.0; IBM, Armonk, NY, USA). Postoperative changes in the KG and VD were analyzed from the amount of relapse using a Wilcoxon signed rank test. Cor-
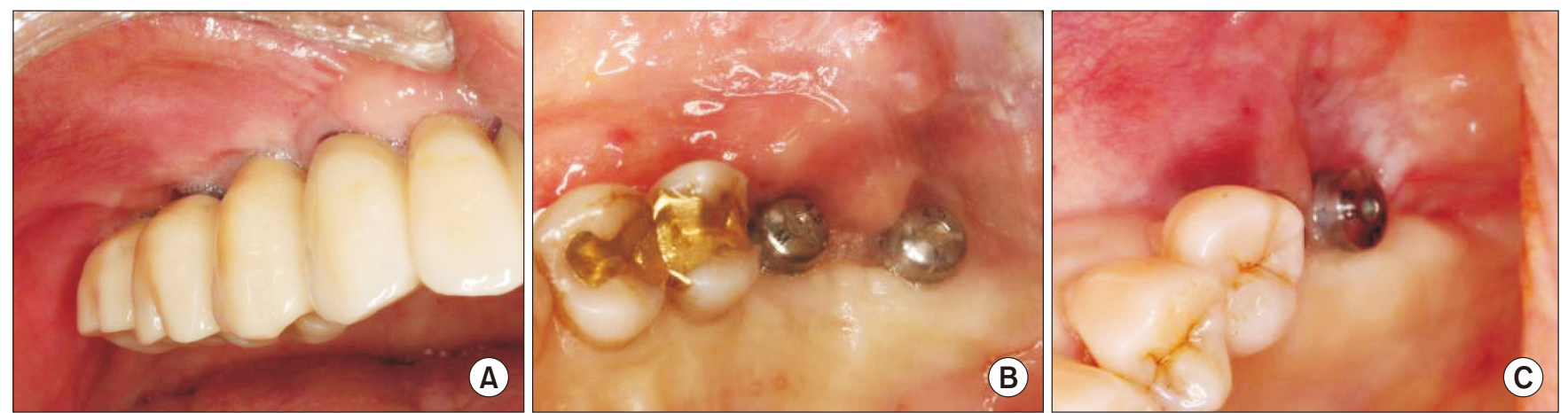

Fig. 1. Lack of keratinized gingiva and vestibular depth due to bone graft and implant surgery. A. Patient \#1. B. Patient \#2. C. Patient \#4. Jeong-Kui Ku et al: Retrospective case series analysis of vestibuloplasty with free gingival graft and titanium mesh around dental implant. J Korean Assoc Oral Maxillofac Surg 2020
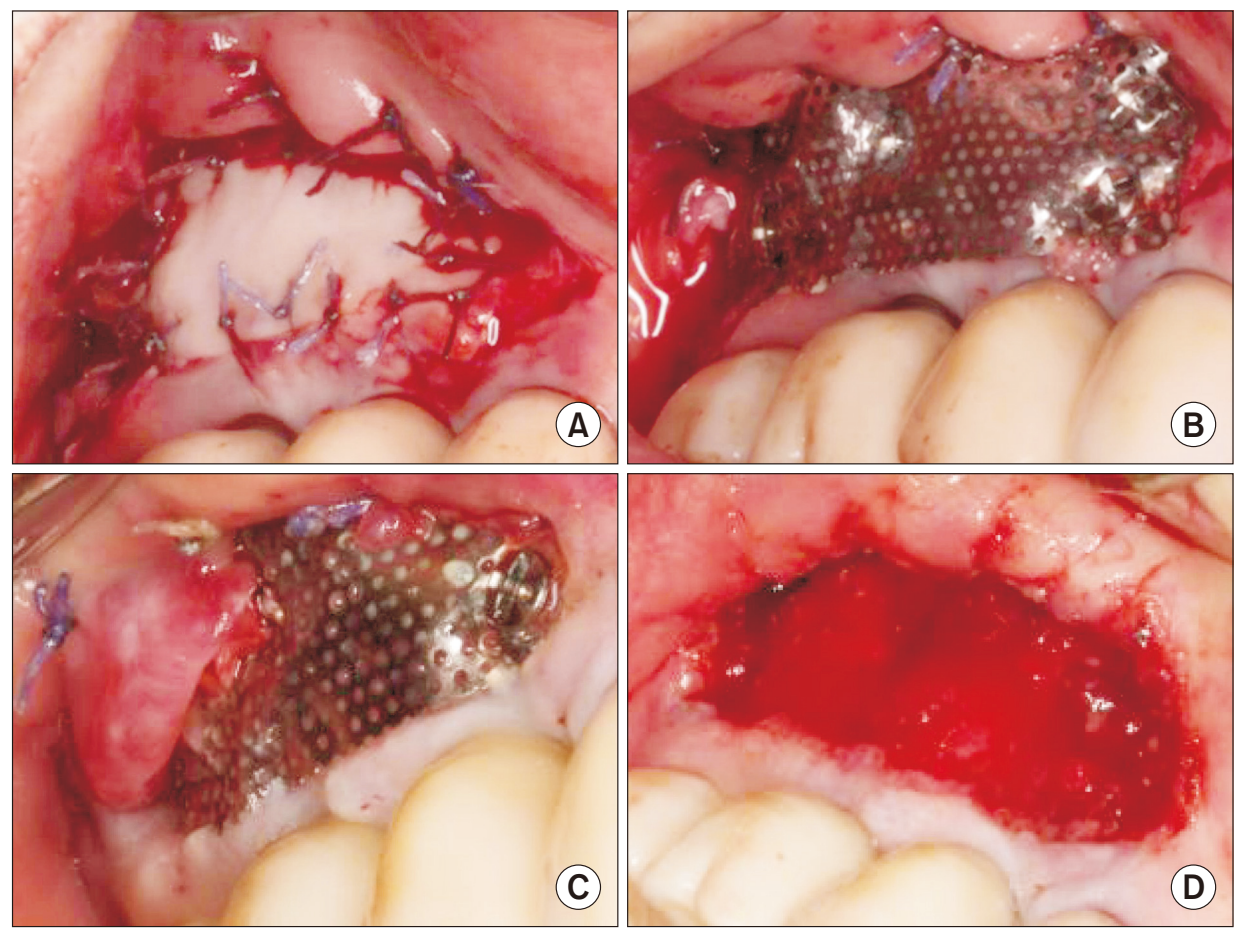

Fig. 2. Vestibuloplasty with free gingival graft and titanium mesh. A. Suturing of the graft onto the recipient periosteum. B. Adaptation of titanium mesh with bone screws. C. Overgrowth of muscular fiber covering the titanium mesh 4.5 weeks postoperative. D. Removal of the titanium mesh and screws, and surplus soft tissue 4.5 weeks postoperative. Jeong-Kui Ku et al: Retrospective case series analysis of vestibuloplasty with free gingival graft and titanium mesh around dental implant. J Korean Assoc Oral Maxillofac Surg 2020 
relations between changes in KG and VD were analyzed using Mann-Whitney $U$ test according to the jaw and sex. The measurement values are expressed as median [interquartile range], and $P$-values less than 0.05 were statistically significant.

\section{Surgical procedure}

The surgical procedure was performed as the described in a previous report ${ }^{6}$. A horizontal incision was made at the mucogingival junction of the recipient site in patient \#1 (Fig. 1. A) and a vertical incision was made approximately $10 \mathrm{~mm}$ toward the vestibule from the mesiodistal end of the horizontal incision. A sharp dissection was made to prevent damage to the periosteum. The detached muscle was sutured with 4-0 Vicryl (Ethicon, Somerville, NJ, USA) at the vestibular fornix to create the recipient bed. A rectangular flap was designed on a hard palate and the thickness of the graft was approximately $1.5 \mathrm{~mm}$.

The graft was placed in the margin of the recipient bed and fixed by interrupted suture with a 5-0 Vicryl. Titanium mesh (depth $0.085 \mathrm{~mm}$ and hole size diameter $0.4 \mathrm{~mm}$; Neo Biotech, Seoul, Korea) was applied after trimming it to the same size of the graft and was fixed with bone screws (Bone Screw System, diameter $1.5 \mathrm{~mm}$ and length $6 \mathrm{~mm}$; Osung MND, Gimpo, Korea).(Fig. 2. A, 2. B) The mesh was removed after four weeks to prevent relapse ${ }^{7}$.(Fig. 2. C) The soft tissue upturned above the mesh was trimmed before removing the mesh.(Fig. 2. D) Clinical follow-ups took place after removal of the mesh.(Fig. 3)

\section{Results}

Ten operations among nine patients $(53.9 \pm 14.1$ years, four males and five females) were included in this study. The patients underwent vestibuloplasty with the method described above $14.2 \pm 7.3$ months after bone graft. Titanium mesh was removed $4.1 \pm 2.5$ weeks after surgery.(Table 1 ) There were no specific complications in any patients.

The median amount of $\mathrm{KG}$ and VD remaining were 5.7 $\mathrm{mm}[3.0 \mathrm{~mm}]$ and $7.8 \mathrm{~mm}$ [3.8 $\mathrm{mm}$ ], respectively, after $34.4 \pm 14.4$ months. In terms of the relapse rate, there was a
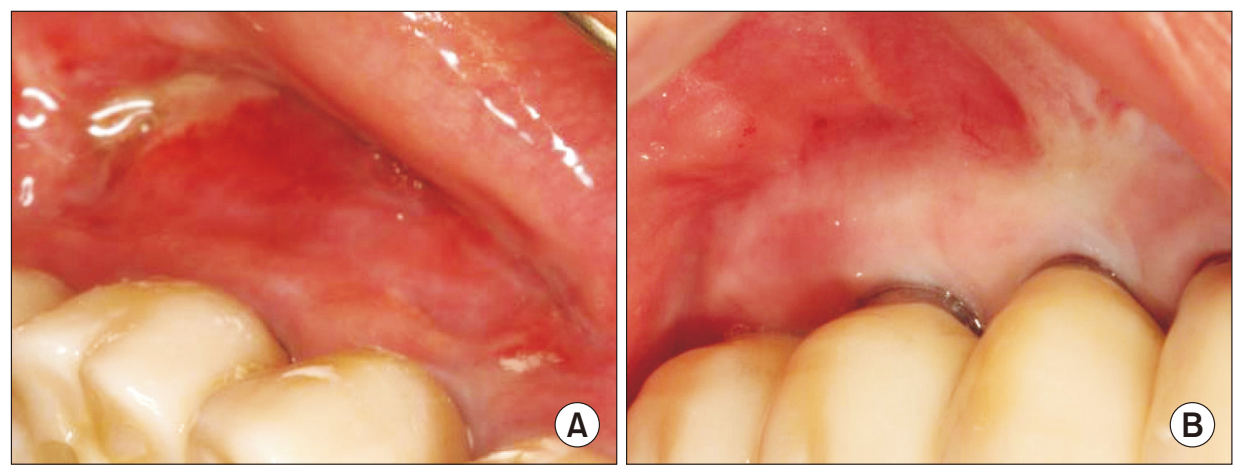

Fig. 3. Follow-up after removal of the titanium mesh. A. Incomplete gingival remodeling 5.5 weeks postoperative. $B$. Sufficient amount of keratinized gingiva and vestibular depth 10 weeks postoperative.

Jeong-Kui Ku et al: Retrospective case series analysis of vestibuloplasty with free gingival graft and titanium mesh around dental implant. J Korean Assoc Oral Maxillofac Surg 2020

Table 1. Demographic and clinical characteristics of vestibuloplasty and free gingival graft covered with titanium mesh

\begin{tabular}{|c|c|c|c|c|c|c|c|c|}
\hline $\begin{array}{l}\text { Patient } \\
\text { No. }\end{array}$ & Sex & Age $(y r)$ & General condition & Location & $\begin{array}{l}\text { Titanium } \\
\text { mesh } \\
\text { maintenance } \\
\text { period } \\
\text { (wk) }\end{array}$ & $\begin{array}{l}\text { Follow-up } \\
\text { period (mo) }\end{array}$ & $\begin{array}{l}\text { Remaining } \\
\text { KG at final } \\
\text { follow-up } \\
\text { (mm) }\end{array}$ & $\begin{array}{l}\text { Remaining } \\
\text { VD at final } \\
\text { follow-up } \\
\quad(\mathrm{mm})\end{array}$ \\
\hline 1 & $\mathrm{~F}$ & 44 & - & Posterior maxilla & 4 & 7 & 6.3 & 6.3 \\
\hline 2 & M & 54 & Hypertension (controlled) & Posterior maxilla & 7 & 28 & 3.3 & 5.3 \\
\hline 3 & $\mathrm{~F}$ & 73 & Burning mouth syndrome & Posterior maxilla & 4 & 34 & 8.0 & 8.0 \\
\hline 4 & $\mathrm{~F}$ & 61 & Hypertension (controlled) & Posterior mandible & 1 & 40 & 6.0 & 9.0 \\
\hline 5 & M & 68 & Diabetes (controlled) & Posterior maxilla & 4 & 41 & 4.0 & 7.7 \\
\hline 6 & M & 66 & Hypertension (controlled) & Posterior maxilla & 1 & 49 & 5.0 & 10.0 \\
\hline \multirow[t]{2}{*}{7} & M & 35 & Smoking, depression & Anterior maxilla & 2 & 41 & 5.3 & 7.7 \\
\hline & & & & Anterior mandible & 7 & 41 & 3.0 & 6.0 \\
\hline 8 & $\mathrm{~F}$ & 51 & - & Posterior mandible & 7 & 50 & 8.0 & 10.0 \\
\hline 9 & $\mathrm{~F}$ & 49 & - & Posterior maxilla & 4 & 13 & 6.0 & 0 \\
\hline
\end{tabular}

(F: female, M: male, KG: keratinized gingiva, VD: vestibular depth)

Values are presented as number or mean.

Jeong-Kui Ku et al: Retrospective case series analysis of vestibuloplasty with free gingival graft and titanium mesh around dental implant. J Korean Assoc Oral Maxillofac Surg 2020 
Table 2. Comparison of the relapse of keratinized gingiva (KG) and vestibular depth (VD) at the final follow-up

\begin{tabular}{|c|c|c|c|c|c|c|}
\hline Parameter & Total & $P$-value & Maxilla $(n=7)$ & $P$-value & Mandible $(n=3)$ & $P$-value \\
\hline $\begin{array}{l}\text { Relapse of KG (\%) } \\
\text { Relapse of VD (\%) }\end{array}$ & $\begin{array}{l}48.3[29.2] \\
23.3[40.0]\end{array}$ & $0.010^{1}$ & $\begin{array}{l}50.0[30.0] \\
23.3[40.0]\end{array}$ & $0.043^{2}$ & $\begin{array}{l}46.7 \text { [NA] } \\
23.3 \text { [NA] }\end{array}$ & - \\
\hline
\end{tabular}

(NA: not available)

${ }^{1}$ Wilcoxon signed rank test with significance at the 0.05 level.

${ }^{2}$ Mann-Whitney U test with significance at the 0.05 level.

Values are presented as median [interquartile range].

Jeong-Kui Ku et al: Retrospective case series analysis of vestibuloplasty with free gingival graft and titanium mesh around dental implant. J Korean Assoc Oral Maxillofac Surg 2020

Table 3. Comparison of the relapse of keratinized gingiva (KG) and vestibular depth (VD) among the sex

\begin{tabular}{lccc}
\hline Parameter & Male $(\mathrm{n}=4)$ & Female $(\mathrm{n}=5)$ & $P$-value \\
\hline Relapse of KG (\%) & $55.0[17.5]$ & $36.6[30.0]$ & $0.036^{1}$ \\
Relapse of VD $(\%)$ & $23.3[35.0]$ & $20.0[38.3]$ & 0.395 \\
\hline Mann-Whitney U test with significance at 0.05 level. \\
Values are presented as median [interquartile range]. \\
Jeong-Kui Ku et al: Retrospective case series analysis of vestibuloplasty with free gin- \\
gival graft and titanium mesh around dental implant. J Korean Assoc Oral Maxillofac \\
Surg 2020
\end{tabular}

significant difference between KG and VD (48.3\% [29.2\%] and $23.3 \%$ [40.0\%], $P=0.010$ ).(Table 2) Of the 10 operations, seven and three were performed in the maxilla and mandible, respectively. The relapse rates of KG and VD were similar in the jaw, but there was a significant difference between the relapse rates of $\mathrm{KG}$ and $\mathrm{VD}$ in the maxilla (50.0\% [30.0\%] and $23.3 \%$ [40.0\%], respectively, $P=0.043$ ).(Table 2 ) The relapse rate of VD was similar between males and females, but the rate of KG varied significantly (55.0\% [17.5\%] among males and $36.6 \%$ [30.0\%] among females, respectively, $P=0.036$ ). (Table 3)

\section{Discussion}

Recently, Halperin-Sternfeld et al. ${ }^{2}$ reported that shallow VD is highly associated with a peri-implant tissue degeneration. Thus, effective vestibuloplasty could contribute to implant success. Because vestibuloplasty with FGG showed a lower relapse rate than allogeneic or collagen matrix graft ${ }^{8}$, we devised a more effective vestibuloplasty with FGG method for reducing relapse. Vestibuloplasty with FGG and titanium mesh showed a lower relapse rate of $23.3 \%$ in terms of VD without complications compared to a previous study'; therefore, this technique could be effective for obtaining adequate VD.

There was, however, a statistically significant difference in relapse rate between KG and VD. Many studies reported the largest shrinkage one to four weeks after $\mathrm{FGG}^{7}$. Therefore, titanium mesh was maintained until 4 weeks to minimize relapse. The median relapse rate of $\mathrm{KG}$ in this study was still $48.3 \%$. This relapse rate was similar to that of previous studies $(38 \%-45 \%)^{10}$. Therefore, the technique presented in this study could achieve an acceptable amount of KG despite the use of mesh over the graft.

In this study, it was possible to obtain rigid fixation with titanium mesh to minimize stitches, which could prevent one pathway of infection, reduce operation time, and allow close contact between the graft and periosteum without dead space. Therefore, this method could effective for lowering the technique sensitivity of FGG, and obtaining adequate $\mathrm{KG}$ and VD. In three patients (\#4, \#6, and \#7 [anterior maxilla]), the mesh was removed early ( 1 week, 1 week, and 2 weeks, respectively) because of screw loosening; despite this, the results for both KG and VD were acceptable.(Table 1) This suggests that titanium mesh may be most effective in the early period after vestibuloplasty.

Titanium is biocompatible and can withstand intraoral conditions of high temperatures and corrosion ${ }^{5}$. It also has sufficient rigidity and flexibility to prevent extensive pressure on the mucosa. Because the mesh does not react physiologically, there were no serious complications associated with the mesh or the newly-grown soft tissue. In addition, the mesh could allow to separate the newly grown fibrous tissues from that of the gingival graft. Therefore, VD could be obtained more effectively than KG by trimming unnecessary tissue when removing the mesh.

One limitation of this study was that a single surgeon performed the protocol. In addition, the patients had an unequal follow-up duration, and the results were not compared to a control group without the mesh. Therefore, a well-designed prospective study with a larger number of patients will be needed to accurately assess the effectiveness of this method. In addition, further research is needed on implant prognosis and oral hygiene management in patients treated using this technique. 


\section{Conclusion}

There were no complications, such as graft failure, after vestibuloplasty with titanium mesh-covered FGG. The mesh did not adversely affect the prognosis of the grafted gingiva or the formation of KG. In addition, the mesh effectively prevented relapse in terms of VD. Vestibuloplasty with FGG using titanium mesh can be used to achieve the appropriate amount of $\mathrm{KG}$ and VD without complications.

\section{ORCID}

Jeong-Kui Ku, https://orcid.org/0000-0003-1192-7066

Dae Ho Leem, https://orcid.org/0000-0001-6735-8275

\section{Authors' Contributions}

J.K.K. and D.H.L. were responsible for the conception and design of the study, and drafting and critical revision of the article. D.H.L. was responsible for acquisition of the data, laboratory or clinical/literature search, and analysis and interpretation of the data collected. All authors read and approved the final manuscript.

\section{Ethics Approval and Consent to Participate}

The study was approved by the Institutional Review Board of Jeonbuk National University Hospital (IRB No. 2017-11002-001), and the informed consent was waived by the IRB.

\section{Conflict of Interest}

No potential conflict of interest relevant to this article was reported.

\section{References}

1. Schwartz-Arad D, Chaushu G. Placement of implants into fresh extraction sites: 4 to 7 years retrospective evaluation of 95 immediate implants. J Periodontol 1997;68:1110-6. https://doi.org/10.1902/ jop.1997.68.11.1110

2. Halperin-Sternfeld M, Zigdon-Giladi H, Machtei EE. The association between shallow vestibular depth and peri-implant parameters: a retrospective 6 years longitudinal study. J Clin Periodontol 2016;43:305-10. https://doi.org/10.1111/jcpe.12504

3. Schmitt CM, Tudor C, Kiener K, Wehrhan F, Schmitt J, Eitner S, et al. Vestibuloplasty: porcine collagen matrix versus free gingival graft: a clinical and histologic study. J Periodontol 2013;84:914-23. https://doi.org/10.1902/jop.2012.120084

4. Bohannan HM. Studies in the alteration of vestibular depth I. Complete denudation. J Periodontol 1962;33:120-8.

5. Wang RR, Fenton A. Titanium for prosthodontic applications: a review of the literature. Quintessence Int 1996;27:401-8.

6. $\mathrm{Ku} \mathrm{JK}$, Leem $\mathrm{DH}$. Vestibuloplasty covering titanium mesh with grafted free gingiva on anterior mandible: technical report and rationale. J Korean Assoc Oral Maxillofac Surg 2019;45:369-73. https://doi.org/10.5125/jkaoms.2019.45.6.369

7. Egli U, Vollmer WH, Rateitschak KH. Follow-up studies of free gingival grafts. J Clin Periodontol 1975;2:98-104. https://doi. org/10.1111/j.1600-051x.1975.tb01730.x

8. Lim HC, An SC, Lee DW. A retrospective comparison of three modalities for vestibuloplasty in the posterior mandible: apically positioned flap only vs. free gingival graft vs. collagen matrix. Clin Oral Investig 2018;22:2121-8. https://doi.org/10.1007/s00784-0172320-y

9. Thoma DS, Benić GI, Zwahlen M, Hämmerle CH, Jung RE. A systematic review assessing soft tissue augmentation techniques. Clin Oral Implants Res 2009;20 Suppl 4:146-65. https://doi.org/10.1111/ j.1600-0501.2009.01784.x

10. Elkhaweldi A, Rincon Soler C, Cayarga R, Suzuki T, Kaufman Z. Various techniques to increase keratinized tissue for implant supported overdentures: retrospective case series. Int J Dent 2015;2015:104903. https://doi.org/10.1155/2015/104903

How to cite this article: $\mathrm{Ku} \mathrm{JK}$, Leem DH. Retrospective case series analysis of vestibuloplasty with free gingival graft and titanium mesh around dental implant. J Korean Assoc Oral Maxillofac Surg 2020;46:417-421. https://doi.org/10.5125/jkaoms.2020.46.6.417 